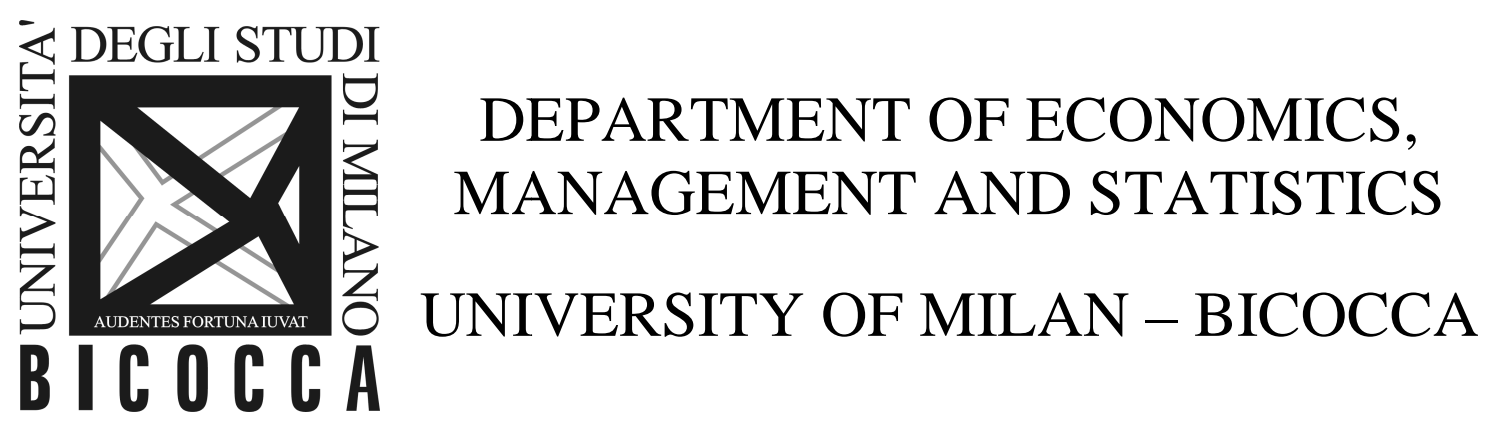

DEMS WORKING PAPER SERIES

\title{
Product market competition and collateralized debt
}

Vittoria Cerasi, Alessandro Fedele, Raffaele Miniaci No. 238 - March 2013

Dipartimento di Economia, Metodi Quantitativi e Strategie di Impresa Università degli Studi di Milano - Bicocca 


\title{
Product market competition and collateralized debt ${ }^{*}$
}

\author{
Vittoria Cerasi ${ }^{a}$
}

\author{
Alessandro Fedele ${ }^{b}$
}

This draft: February 15, 2013

\author{
Raffaele Miniaci ${ }^{c}$
}

\begin{abstract}
This paper presents a model where bank credit depends upon borrowers' product market structure. We show that a larger number of competitors in the industry may increase credit availability by enhancing the resale value of the collateralized productive assets. We also study how this benefit of competition is affected by the existence of outsiders willing to bid for the collateralized productive assets of the insiders. Our model encompasses the standard case of Cournot competition either when the default probability goes to zero or when there are multiple outsiders bidding for the productive assets. We test the empirical implications of the theoretical analysis exploiting information on the access to finance of small and medium Italian firms and find supportive evidence.
\end{abstract}

JEL classification: D22 (Firm Behavior: Empirical Analysis); L13 (Oligopoly); G33 (Liquidation).

Keywords: collateralized loans; product market competition; productive assets resale value.

${ }^{*}$ Acknowledgements. We appreciated comments from participants in the Conference "Liquidity, Banking and Financial Markets", Bologna University, Bologna (June 2012) and in the 39th Annual Conference of the European Association for Research in Industrial Economics (EARIE 2012), Luiss University, Rome (September 2012) and especially from our discussant Joao Montez.

${ }^{\dagger a}$ Corresponding author: Milano-Bicocca University, Economics Department, Via Bicocca degli Arcimboldi 8, 20126 Milano, Italy; e-mail: vittoria.cerasi@unimib.it; phone: +39-02-6448-5821; fax: +39-02-6448-5878.

${ }^{b}$ Libera Università di Bolzano, Facoltà di Economia, piazza Università 1, 39100 Bolzano, Italy; e-mail: alessandro.fedele@unibz.it.

${ }^{c}$ Università degli Studi di Brescia, Dipartimento di Scienze Economiche, Via S.Faustino 74/b, 25122 Brescia, Italy; e-mail: miniaci@eco.unibs.it. 


\section{Introduction}

External finance is a vital ingredient for firms willing to undertake productive investments. The cost of external finance however varies across countries and industries and dampens firms' growth especially for what concerns small and medium enterprises (SMEs) as shown by Rajan and Zingales (1998). Policy makers seeking solutions to curtail credit rationing, have considered so far ways to reduce opaqueness of SMEs or to improve bank long-term relationship (see Berger and Udell, 1995). We explore a different channel: we suggest that increasing competition in the product market or, alternatively, opening the access to second-hand markets of productive assets to outside bidders might improve SMEs' ability to raise external funding.

The aim of this paper is to understand how external finance is affected by the structure of the product market in which firms compete. The amount of firms' external finance available to undertake new investments depends upon the pledgeable income to creditors as extensively illustrated by Holmstrom and Tirole (1997). Greater competition in the product market, by shrinking profits, reduces the amount that can be pledged to creditors and hence it is not beneficial.

However firms may boost further their borrowing capacity by collateralizing productive assets (PAs, henceforth). In the case of collateralized loans, before extending credit, lenders consider not only firms' expected profitability but also the resale value of collateralized PAs, which in case of distress can be seized and liquidated. In this context, the resale value of PAs plays a crucial role, as proved by evidence in Almeida and Campello (2007), Ortiz-Molina and Phillips (2009) and Benmelech and Bergman (2009). One of the most important determinants of such a value is the existence of competitors in the product market willing to acquire the PAs in order to reuse them in the production.

However, not only the competitors' mere existence but also their financial strength is crucial. Shleifer and Vishny (1992) were the first to notice that the state of health of rivals in the same industry might affect the resale value of productive equipments. Support to this can be found in the evidence provided by Acharya et al. (2007) who measure how industry characteristics affect recovery rates of PAs.

In this paper we propose a theoretical framework to study the relation between collateralized lending and the structure of the product market and we test the main predictions of the model on a sample of Italian SMEs. In the model firms competing à la Cournot in their product market apply for loans from lenders in order to undertake productive projects and post their PAs as collateral in the loan. Each productive project is risky since it may fail with a positive probability, in which case lenders will not be repaid. Default probabilities are independent across firms. Lenders after extending the loan, might learn that the project will fail; in this case the lender seizes the collateralized PAs and liquidates them before production takes place. The PAs are traded in an auction where successful rivals and outside firms are the potential buyers. 
Given that several PAs may be liquidated when idiosyncratic shocks hit several projects at the same time, the resale value of the PAs depends upon the number of bidders and the number of assets on sale in the second-hand market. We show that the equilibrium quantities in the competition stage depart from the standard Cournot equilibrium due to the non-zero probability of default, while encompassing it when such a probability is zero.

Our main finding is that the amount of credit, and therefore the equilibrium quantity, might be increasing in the number of rivals: this effect fades away as the number of rivals becomes relatively large. The intuition rests on the existence of the following trade-off. On the one hand, as the initial number of rivals rises, there is an increasing number of states in which firms may be healthy and can bid for the PAs: this increases the expected recovery value of PAs and enhances the pledgeable income to lenders. On the other hand, profits fall with competition, thus shrinking in equilibrium the amount of credit. The positive effect is shown to outdo the negative effect for an increasing although relatively small number of firms in the same market.

This effect captures the idea of an increasing liquidity of productive assets used as collateral in the debt contract. In the model we show that the existence of rivals outside the industry interested in acquiring the productive asset reduces this effect of internal product market competition by enhancing the resale value of PAs.

In the second part of the paper we test the main predictions of the model on a sample of Italian SMEs. We use a survey on access to finance where a sample of Italian SMEs are asked about the way they finance their productive investments. We apply a probit model with sample selection to test the amount of bank debt conditional on the decision to invest and find evidence that greater product market competition, measured as a low Herfindahl index in the sector where the firm operates, increases the amount of bank credit to SMEs. We also find that the positive effect of greater product market competition on credit availability is smaller in industries with outside rivals.

The results in the paper have important implications for the availability of external finance to SMEs. In phases where bank credit shrinks, due for instance to a credit crunch, it might be important to know alternative ways to improve access to finance. We suggest that policies aiming at promoting competition in the product market or alternatively at simplifying the access to second-hand market of PAs for outside bidders have the desiderable effect of increasing credit availability for SMEs.

Related literature. This paper is closely related to Shleifer and Vishny (1992) for the idea that the firms' PAs are mostly valuable for competitors in the same industry and that credit constrained firms can increase their debt capacity when the recovery rate of their PAs is greatest, that is when direct rivals are in the position to bid for the assets. ${ }^{1}$ Our paper adds the consideration that the competitive environment

\footnotetext{
${ }^{1}$ Empirical support to this prediction is provided by Habib and Johnsen (1999), Ortiz-Molina and Phillips (2009) and Gavazza $(2010)$.
} 
of the product market is relevant to determine both the level of profitability and the recovery value of PAs. Almeida et al. (2009) develop a model with independent liquidity shocks, similar to the one in this paper, in order to study the availability of credit lines for firms with industry-specific PAs, however they ignore product market competition.

In the literature that relates credit availability to product market competition (see, e.g., Brander and Lewis, 1986), the focus is on the impact of external finance on competitive behavior of firms in the product market. The novelty in our paper is to explore the reverse causality, that is the impact of product market competition on external finance. We are not aware of other papers where this feedback is explored, except Cerasi and Fedele (2011): we depart from our first contribution where we studied a model with moral hazard between creditors and entrepreneurs in a duopoly setting, by extending the analysis to the case in which a large number of firms compete in the product market with perfect symmetric information.

The remainder of the paper is organized as follows. Section 2 describes the setup of the model. After presenting an example with three firms in section 3, we describe the general case with $N$ firms and in section 4 we derive the equilibrium. Section 5 studies the properties of that equilibrium; while in section 6 we extend the model to the case with outsiders competing for the ownership of the PAs. The empirical analysis is presented in section 7 , while section 8 concludes the paper.

\section{The economy}

Consider $N \geq 2$ incumbent firms competing à la Cournot for the sale of an homogeneous good. At date 0 each firm $i=\{1, \ldots, N\}$ invests $I_{i}$ to undertake a risky productive project. At date 1 the project returns a positive cash flow $P_{N} \times q_{i}$ with probability $p \in(0,1)$ or 0 otherwise: $q_{i}$ denotes the quantity of the good supplied by firm $i ; P_{N} \equiv S-b \sum_{i=1}^{N} q_{i}$ is the inverse demand function, where $S>0$ is the overall market size and parameter $b>0$ measures how the price $P_{N}$ is affected by changes in total quantity $\sum_{i=1}^{N} q_{i}$. Probabilities of success $p$ are identical and independent across firms. Initial investment $I_{i}$ is the minimum expenditure to acquire PAs in order to supply $q_{i}$. The functional relationship between $I_{i}$ and $q_{i}$ is as follows

$$
q_{i}=\sqrt{I_{i}}
$$

with $q_{i}^{2}$ thus denoting the total production cost.

Firm $i$ owns limited funds $M<I_{i}$ : the residual amount $I_{i}-M$ is borrowed from a competitive banking sector at date 0 . The financial agreement is a collateralized debt contract, with $r_{i}$ denoting the repayment to the bank by firm $i$ at date 1 . We let $0<r_{i}<P_{N} q_{i}$, so that firm $i$ repays the amount $r_{i}$ with probability $p$ and defaults with probability $1-p$. Banks are informed creditors since at an interim date $1 / 2$ they receive a perfect signal about the future realization of the project cash flow. ${ }^{2}$ A negative signal is received with

\footnotetext{
${ }^{2}$ In the literature there are justifications for this assumption. For instance Rajan (1992) assumes that banks are informed
} 
probability $1-p$, in which case a bank, anticipating that the borrower will not be able to repay the debt, since the cash flow will be zero, seizes the failing firms' PAs, sells them in the second-hand market and cashes the liquidation value. The PAs are traded in an auction, whose details are described in the next section and where healthy (successful) incumbent firms are the sole potential buyers of distressed competitors' PAs; in section 6 we extend the analysis to the case where also outside firms can acquire PAs with the objective to enter the market. ${ }^{3}$

Before proceeding, we specify the timing of events.

- At date 0 each firm $i$ invests own funds $M$ and borrows $I_{i}-M$ from a competitive banking sector to undertake a productive project. Afterwards, each firm $i$ sets the Cournot equilibrium quantity $q_{i}$.

- At interim date $1 / 2$ banks receive a perfect signal about the future realization of project's cash flow: in case of a negative signal the bank seizes the PAs and sells them to the healthy rivals.

- At date 1 healthy firms compete in the product market using the PAs resulting from the relocation of ownership at date $1 / 2$.

It is worth anticipating that although $N$ symmetric firms are initially active in the industry at date 0 , the structure of the product market at date 1 might be asymmetric where firms of different sizes cohexist: as a matter of fact, such an ex-post structure is determined through the realized transfers of ownership of the failed rivals' PAs among healthy firms.

\section{An example with three firms}

To make the principal idea easier to follow, we now introduce the Cournot equilibrium analysis in the special case of three incumbents at date 0 , while postponing the generalization of the main result to the case of $N$ firms in the next section.

We first describe the details of the auction through which the ownership of the PAs is transferred. To this aim, we list in the following table all possible alternatives after the signal is known at date $1 / 2$ and the associated probabilities at date 0 , by selecting firm 1 as the representative firm:

\begin{tabular}{|l|l|l|}
\hline & firm 1 is healthy & firm 1 is failing \\
\hline firms 2 and 3 are healthy & $p \times p^{2}$ & $(1-p) \times p^{2}$ \\
\hline either firm 2 or 3 is healthy & $p \times 2 p(1-p)$ & $(1-p) \times 2 p(1-p)$ \\
\hline both firms 2 and 3 are failing & $p \times(1-p)^{2}$ & $(1-p) \times(1-p)^{2}$ \\
\hline
\end{tabular}

creditors compared to other "arm's-lenght" creditors In his paper for instance bondholders do not have any incentive to collect information once they have extended the loan, while banks intervene to liquidate projects since they collect information and have private information about the realizations of future cash flow.

${ }^{3}$ The default state is due to a firm's specific shock. As a consequence, when the ownership of the PAs is transferred from a defaulted firm to a successful one, their value can be restored. This is to be interpreted as a shock related to human rather than to physical capital, in line with Cerasi and Fedele (2011). 
where the first term of the product in each cell indicates the probability that the event in the column occurs. Defining $H$ (resp. $2-H$ ) the number of rivals whose banks receive a positive (resp. negative) signal at date $1 / 2$, we can resort to a binomial function to write the probability that firm 1 in addition to $H$ firms are healthy:

$$
\left(\begin{array}{c}
2 \\
H
\end{array}\right) p^{H+1}(1-p)^{2-H}
$$

where the binomial coefficient $\left(\begin{array}{l}2 \\ H\end{array}\right)$ indicates the number of times that such a scenario occurs, depending on the specific identity of the $H$ healthy firms. For instance, if $H=1$ expression (3) rewrites as $\left(\begin{array}{l}2 \\ 1\end{array}\right) p^{2}(1-p)$ and $\left(\begin{array}{l}2 \\ 1\end{array}\right)=2$ indicates that, beside firm 1 , the other healthy firm may be either firm 2 or firm 3 .

We assume that all the healthy firms participate in the auction and they bid for all available PAs. Given that firms are credit constrained, it is their banks who grant additional funds to enable them to participate in the auction. The maximum amount of such a loan, i.e. the money firms are willing to bid for distressed competitors' PAs, is determined as follows. We focus on date $1 / 2$ and assume that firm 1 is healthy: when both rivals fail $(H=0)$, firm 1 is willing to bid up to its reservation value for PAs of firms 2 and 3 , that is

$$
P_{3} \times 3 \bar{q}-P_{1} \times \bar{q}
$$

where $\bar{q}$ denotes the symmetric 3-oligopoly Cournot equilibrium quantity, which is set at date 0 . The first term is firm 1's revenue after the acquisition of both PAs, where $P_{3} \equiv S-b 3 \bar{q}$ indicates the demand function. The second term is the revenue when firm 1, the only potential participant in the auction, decides not to buy the PAs: in such a case (the status quo) the assets are lost and exit the market, hence industry quantity is simply $q_{1}=\bar{q}$ and price is $P_{1} \equiv S-b \bar{q}$. We will show that at the Cournot equilibrium the following inequality holds true,

$$
P_{3} 3 \bar{q}-P_{1} \bar{q}>0
$$

hence firm 1 is willing to bid for both assets in case it is the only healthy firm. Two observations: first, we disregard production costs $q_{i}^{2}$ when writing (4) since such costs are sunk, i.e. they are borne by any firm $i$ at date 0 ; second, computation of (4) is driven by the timing of our game according to which quantities $q_{2}=q_{3}=\bar{q}$ are chosen by firms 2 and 3 before date $1 / 2$ and they cannot be modified by the acquiring firm 1 after date $1 / 2$.

When instead only one rival fails $(H=1)$, say either firm 2 or 3 , firm 1 's reservation value is

$$
P_{3} 2 \bar{q}-P_{3} \bar{q}=P_{3} \bar{q}>0
$$

The first term can be explained similarly to the previous case, mutatis mutandis. The second term differs because at least another bidder, either firm 3 or 2 , is active: if firm 1 decides not to buy, the rival gets the PAs since it has the same positive reservation price $P_{3} \bar{q}$, in which case industry quantity is $3 \bar{q}$ and price is $P_{3} \equiv S-b 3 \bar{q}$. 
We now turn to the computation of the equilibrium resale value of a failing firm's PAs. We base our argument on Bertrand competition to justify that, when there are at least two bidders with the same reservation value, the equilibrium bid equates (6). The equilibrium bid in a single-bidder auction is instead $\varepsilon$, where $\varepsilon$ is positive but small. Obviously if all firms or none of them is healthy there is no transfer of assets and the equilibrium bid is zero. Summing up, in equilibrium the bid for a failing firm's PAs is either

$$
v_{3}(1, H) \equiv\left\{\begin{array} { l l } 
{ 0 } & { \text { if } H = 2 , } \\
{ P _ { 3 } \overline { q } } & { \text { if } H = 1 , } \\
{ \varepsilon } & { \text { if } H = 0 }
\end{array} \quad \text { or } v _ { 3 } ( 0 , H ) \equiv \left\{\begin{array}{ll}
P_{3} \bar{q} & \text { if } H=2 \\
\varepsilon & \text { if } H=1, \\
0 & \text { if } H=0,
\end{array}\right.\right.
$$

where the argument within brackets $(1, H)$ indicates that firm 1 plus $H$ firms are healthy, whilst $(0, H)$ that firm 1 is failing, while $H$ firms, beside firm 1, are healthy. Finally, in case of tie in the bids, the ownership of (indivisible) PAs is randomly allocated to a single bidder. ${ }^{4}$

We are now able to write firm 1's expected revenue at date 0 by anticipating that at the symmetric Cournot equilibrium all firms but 1 choose the same quantity $\bar{q}$ :

$$
\begin{aligned}
U_{1}=p\left(P_{3} q_{1}-r_{1}\right)+p\left\{p^{2} \times 0+\right. & {\left.\left[p(1-p) \frac{1}{2} P_{3} \bar{q}+(1-p) p \frac{1}{2} P_{3} \bar{q}\right]+(1-p)^{2} P_{3}(2 \bar{q})\right\} } \\
& +(1-p) \times 0-M .
\end{aligned}
$$

When firm 1 is healthy (with probability $p$ ), it earns $P_{3} q_{1}$ and repays $r_{1}$ to the bank. In addition, when both rivals are healthy (with probability $p^{2}$ ) there are no PAs for sale, hence firm 1 earns no extra-profits. When either firm 2 or firm 3 fails (with probability $p(1-p)$ each) firm 1 acquires the failing rival's PAs with probability $\frac{1}{2}$ and earns $P_{3} \bar{q}$ in each case. When both rivals fail (with probability $(1-p)^{2}$ ) firm 1 buys the two PAs of failing rivals and gains $P_{3} 2 \bar{q}$. By contrast, when firm 1 fails (with probability $(1-p)$ ) it earns nothing due to limited liability. Finally, $M$ denotes the opportunity cost of firm 1's own funds.

The expected profit of a bank that lends to firm 1 is

$$
\begin{aligned}
V_{1}=p\left\{r_{1}-\right. & {\left.\left[p(1-p) \frac{1}{2} v_{3}(1,1)+(1-p) p \frac{1}{2} v_{3}(1,1)\right]-(1-p)^{2}\left(v_{3}(1,0)+v_{3}(1,0)\right)-p^{2} v_{3}(1,2)\right\} } \\
& +(1-p)\left[p^{2} v_{3}(0,2)+2 p(1-p) v_{3}(0,1)+(1-p)^{2} v_{3}(0,0)\right]-\left(I_{1}-M\right) .
\end{aligned}
$$

When firm 1 is successful (with probability $p$ ) the bank receives $r_{1}$. Moreover, when either rival 2 or 3 fails (with probability $p(1-p)$ each) the bank lends an extra amount $\frac{1}{2} v_{3}(1,1) \equiv \frac{1}{2} P_{3} \bar{q}$ to acquire the PAs of the failing rival, $1 / 2$ being the probability that firm 1 is actually awarded firm $j$ 's PAs. With probability $(1-p)^{2}$ the bank funds the price $v_{3}(1,0)+v_{3}(1,0) \equiv 2 \varepsilon$ to acquire the PAs of both failing rivals in a single-buyer auction. When both rivals are healthy (with probability $p^{2}$ ) no trade of PAs occurs, thus $v_{3}(1,2) \equiv 0$.

By contrast, firm 1 fails with probability $1-p$ and: both rivals are healthy (with probability $p^{2}$ ) the bank sells firm 1's PAs at price $v_{3}(0,2) \equiv P_{3} q_{1}$ in a multiple-buyer auction; with probability $2 p(1-p)$ only

\footnotetext{
${ }^{4}$ This is (mathematically) equivalent to assume that PAs are instead divisible and that their ownership is uniformly shared among all bidders.
} 
one rival, either 2 or 3 , is healthy and buys at price $v_{3}(0,1) \equiv \varepsilon$ in a single-buyer auction; with probability $(1-p)^{2}$ both rivals are failing, in which case the PAs cannot be sold, $v_{3}(0,0) \equiv 0$. Finally, last term $I_{1}-M$ is the opportunity cost of the amount lent to firm 1 .

Substituting $I_{1}=q_{1}^{2}$ from (1) and equilibrium bids from (7), the bank's revenue $V_{1}$ can be written as

$$
V_{1}=p r_{1}+p^{2}(1-p) P_{3}\left(q_{1}-\bar{q}\right)-\left(q_{1}^{2}-M\right)
$$

At date 0 the three firms simultaneously choose $q_{i}$ and $r_{i}$ to maximize $U_{i}$, given the banks' participation condition $V_{i} \geq 0$. Full bargaining power in the hands of the firm is justified by the fact that the banks are competitive. Given symmetry, we focus on firm 1 whose expected profit $U_{1}$ is decreasing in $r_{1}$. As a consequence, $r_{1}$ is set as low as possible. Since $V_{1}$ instead increases with $r_{1}$, constraint $V_{1} \geq 0$ must be binding at the symmetric Cournot equilibrium. Solving $V_{1}=0$ by $r_{1}$ and substituting it into (8) gives, after rearranging,

$$
U_{1}=\left[p+(1-p) p^{2}\right] P_{3} q_{1}+p(1-p)^{2} P_{3} 2 \bar{q}-q_{1}^{2} .
$$

The previous expression collapses to the expected surplus of firm 1 when the bank breaks-even, and can be explained as follows: firm 1 earns $P_{3} q_{1}$ when either it is successful (with probability $p$ ) or when it fails but the two healthy rivals bid for firm 1's PAs in an auction with two bidders (with probability $\left.(1-p) p^{2}\right)$. In addition firm 1 gains an extra revenue when, by being healthy, participates in a single-bidder auction and acquires both rivals' PAs (with probability $p(1-p)^{2}$ ). In all other cirumstances the overall gain is zero since either no trade of PAs occurs, or the PAs' equilibrium bid coincides with the firm's reservation value given Bertrand competition in the auction. The last term is the cost of producing the quantity $q_{1}$.

To compute the Cournot equilibrium quantity we take the derivative of (10) with respect to $q_{1}$ for given quantities set by rivals at the equilibrium level $\bar{q}$. In the symmetric equilibrium all quantities are equal to

$$
\bar{q}=S \frac{p\left(1+p-p^{2}\right)}{2+b\left(6 p-2 p^{3}\right)} .
$$

We can easily verify that condition (5) is fulfilled at equilibrium. ${ }^{5}$ As a final remark, it should be noticed that the standard Cournot equilibrium quantity with quadratic production costs $q^{2}$ can be recovered as a special case of (11) when $p=1$, namely $\bar{q}=\frac{S}{2+4 b}$.

\section{Cournot equilibrium}

In this section we generalize the previous result to the case of $N$ incumbent firms at date 0 . Following the exposition in the previous section, we focus on a representative firm $i$ and denote with $H(N-1-H)$

\footnotetext{
${ }^{5}$ Substituting $\bar{q}$ into (5), i.e. firm 1's reservation value for PAs of firms 2 and 3, yields

$$
2 \bar{q} \times S \frac{1+b p[1-p(2-p)]}{1+b p\left(3-p^{2}\right)},
$$
}

which is positive. 
the number of remaining $N-1$ firms whose banks receive a positive (negative) signal at the interim date $1 / 2$. The following table represents the possible alternative scenarios after date $1 / 2$ and the corresponding probabilities according to the binomial distribution:

\begin{tabular}{|l|l|l|}
\hline & firm $i$ is healthy & firm $i$ is failing \\
\hline $\begin{array}{c}H \text { firms are healthy and } \\
(N-1-H) \text { are failing }\end{array}$ & $p \times\left(\begin{array}{c}N-1 \\
H\end{array}\right) p^{H}(1-p)^{N-1-H}$ & $(1-p) \times\left(\begin{array}{c}N-1 \\
H\end{array}\right) p^{H}(1-p)^{N-1-H}$ \\
\hline
\end{tabular}

The table is a generalization of (2), with $N$ instead of 3 . The first term of the product in each cell refers to the probability of the event in the column.

To calculate the bidders' reservation values in the auction for distressed firms' PAs we assume that firm $i$ is healthy at date $1 / 2$ and denote by $q^{*}$ the symmetric $N$-oligopoly Cournot quantity chosen at date 0 by all firms. Firm $i$ 's reservation value for PAs of failing firms is

$$
P_{N} N q^{*}-P_{1} q^{*} \quad \text { when } H=0
$$

and

$$
P_{N}(N-H) q^{*}-P_{N} q^{*}=P_{N}(N-1-H) q^{*}>0 \quad \text { when } H \geq 1
$$

The second term in each difference depends upon the number of healthy firms. When $H=0$ only firm $i$ participates in the auction: (12) is equivalent to (4), with $N$ instead of 3 and $q^{*}$ instead of $\bar{q}$. We will show that in the Cournot equilibrium the following condition holds true

$$
P_{N} N q^{*}-P_{1} q^{*}>0
$$

hence firm $i$ is willing to bid if it is the only healthy firm. By contrast, when $H \geq 1$ there is at least another bidder for the PAs since it has the same reservation positive price: (13) is equivalent to (6), with $N$ instead of 3 and $q^{*}$ instead of $\bar{q}$. Finally, similarly to (7) we compute the equilibrium bid for a failing firm's PAs when there are $N$ initial firms in the industry:

$$
v_{N}(1, H) \equiv\left\{\begin{array} { l l } 
{ 0 } & { \text { if } H = N - 1 , } \\
{ P _ { N } q ^ { * } } & { \text { if } H \in [ 1 , N - 2 ] , } \\
{ \varepsilon } & { \text { if } H = 0 , }
\end{array} \text { and } v _ { N } ( 0 , H ) \equiv \left\{\begin{array}{ll}
P_{N} q^{*} & \text { if } H \in[2, N-1] \\
\varepsilon & \text { if } H=1, \\
0 & \text { if } H=0,
\end{array}\right.\right.
$$

where $(1, H)$ indicates that firm $i$ plus $H$ firms are healthy and $(0, H)$ that firm 1 is failing, while $H$ firms, beside firm $i$, are healthy.

The equilibrium quantity can be computed by choosing the quantity that maximizes the expected surplus of the entrepreneur given that the bank breaks-even, that is:

$$
U_{i}=\left[p+(1-p) \sum_{H=2}^{N-1}\left(\begin{array}{c}
N-1 \\
H
\end{array}\right) p^{H}(1-p)^{N-1-H}\right] P_{N} q_{i}+p(1-p)^{N-1} P_{N}(N-1) q^{*}-q_{i}^{2}
$$

The previous formula can be interpreted similarly to (10). Firm $i$ earns $P_{N} q_{i}$ when either it is successful (with probability $p$ ) or when it fails and at least two rivals are healthy (with probability given by the binomial 
function when there are $H \geq 2$ bidders among $N-1$ firms), thus bidding $v_{N}(0, H) \equiv P_{N} q_{i}$ to acquire firm $i$ 's PAs. In addition firm $i$ gains an extra revenue when, by being healthy, bids in a single-bidder auction and acquires all $N-1$ failing rivals' PAs (with probability $p(1-p)^{N-1}$ ). In all other cirumstances the overall gain is zero. The last term is the cost of producing the quantity $q_{i}$. Taking the derivative with respect to $q_{i}$, when all rivals set their quantity at the equilibrium level $q^{*}$, yields the symmetric Cournot equilibrium quantity in a $N$-oligopoly:

Proposition 1 When only incumbent firms participate in the auction for productive assets, the symmetric equilibrium quantity in the Cournot game with $N$ firms is

$$
q^{*}=S \frac{1-(1-p)^{N-1}[1+p(N-2)]}{2+b\left\{N+1-(1-p)^{N-1}\left[N+1+p(N-1)^{2}-2 p\right]\right\}}
$$

Proof. In the Appendix.

This is the equilibrium quantity in a Cournot game where each firm faces an independent and idiosyncratic probability of failure. As a matter of fact, the quantity in (17) collapses to the standard Cournot equilibrium quantity with production $\operatorname{costs} q^{2}$ when $p=1$ :

$$
q^{*}=\frac{S}{2+b(N+1)} .
$$

This implies that the possibility of trading PAs affects the quantity chosen at the equilibrium through the expectation of what can be recovered from the sale of the PAs in the event of a failure. This is the crucial mechanism at work in our model that, for some constellations of parameters, might reverse the standard negative effect of a declining equilibrium quantity as the number of firms in the industry increases.

\section{Comparative statics}

In this section we discuss how lending is affected by greater competition in the product market. To this aim, we need to relate the Cournot equilibrium quantity $q^{*}$ in (17) with measures of credit availability. One possible measure is the proportion of new debt on total investment, that is :

$$
L=\frac{I-M}{I}
$$

Recalling equation (1), this amounts to

$$
L^{*}=\frac{\left(q^{*}\right)^{2}-M}{\left(q^{*}\right)^{2}}=1-\frac{M}{\left(q^{*}\right)^{2}} .
$$

The above expression shows that the proportion of new debt on investment $L^{*}$ increases with $q^{*}$. Accordingly, we can derive predictions on how $L^{*}$ is affected by the structure of the product market straight from the results on the equilibrium quantity $q^{*}$ in $(17)$. 
We measure competition through an increase in $N$, i.e the number of incumbent firms at date 0 . Given the complicate formula of (17), we do not compute directly the derivative $\frac{\partial q^{*}}{\partial N}$. Rather we provide some numerical examples by assigning different values to the two parameters $p$ and $b$ and then plotting $q^{*}$ in plane $\left(N, q^{*}\right)$. With no loss of generality, we normalize the market size by setting $S=1$. In Figure 1 we draw the equilibrium quantity $q^{*}$ as a function of $N$, when $b=0.1$ and $p$ takes different values.

\section{FiguRE 1}

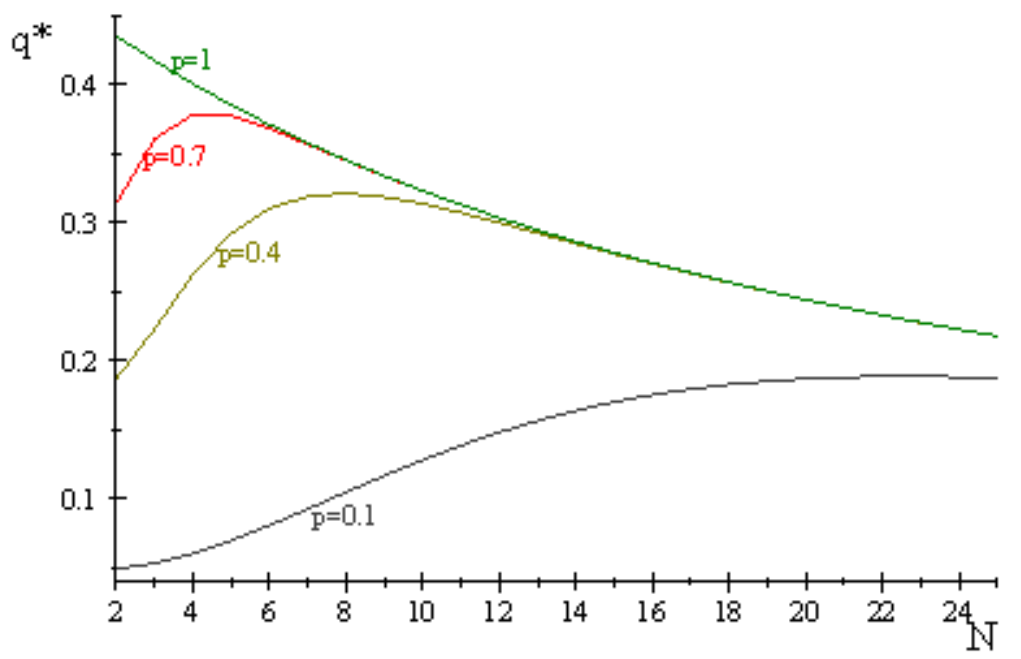

In Figure 2 instead the equilibrium quantity $q^{*}$ is plotted as a function of $N$, when $p=0.5$ and $b$ takes different values. 
FiguRE 2

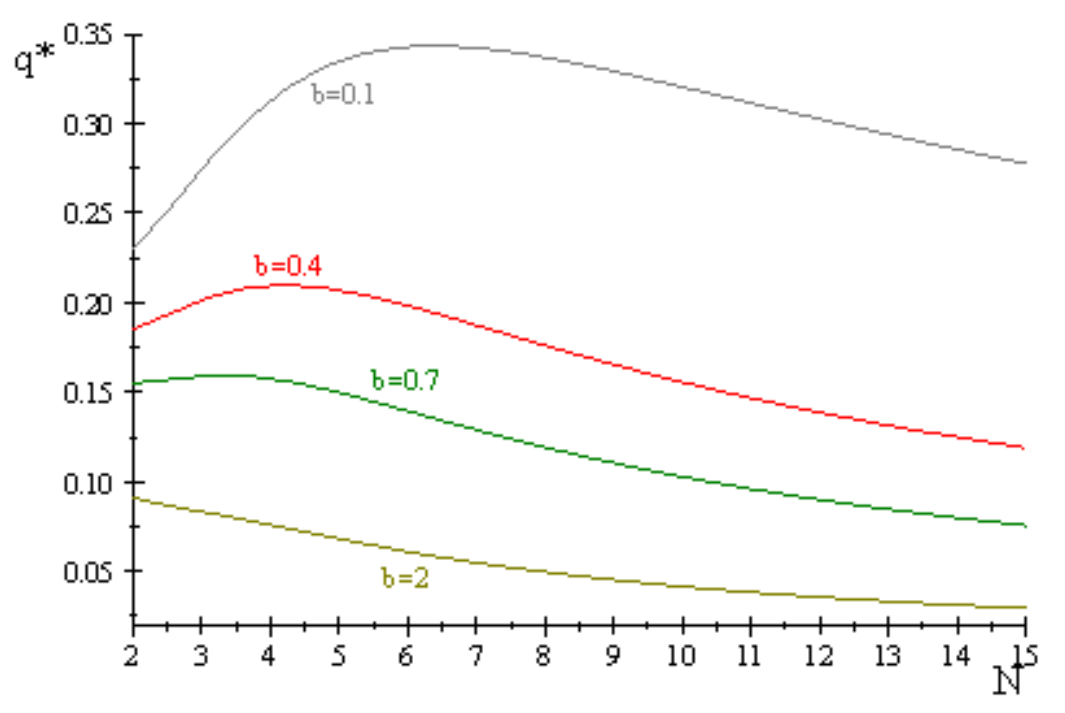

Both figures show that the relation between the equilibrium quantity $q^{*}$ (and thus the proportion of new debt over investment $L^{*}$ ) and the number of firms $N$ is non-monotonic. More precisely, for small values of $N$ tougher competition, i.e. more firms active at date 0 , affects positively $q^{*}$ and $L^{*}$. For large values of $N$ tougher competition reduces the equilibrium quantity $q^{*}$ and $L^{*}$.

This result can be explained by the following trade-off. On the one hand, the number of states in which at least one firm is healthy and qualified to bid for PAs increases with $N$ : this has a positive effect on the expected PAs' liquidation price and, in turn, on $q^{*}$ and $L^{*}$. On the other hand, the equilibrium price $P_{N} \equiv S-b N q^{*}$ decreases with $N$, thus shrinking $q^{*}$ and $L^{*}$. The positive effect is shown to outdo the negative effect only for small values of $N$.

Focusing on $L^{*}$ and summing up

Proposition 2 The relation between proportion of new debt on the investment and competition, in terms of number $N$ of active firms at date 0 , is non monotonic: for relatively small values of $N$ the proportion of new debt in equilibrium $L^{*}$ increases with $N$; while for relatively large values of $N$ it decreases with $N$.

In addition, Figure 1 shows that the optimal degree of competition, i.e. the number of firms $N$ that maximizes $q^{*}$, decreases with the success probability $p$. In the limit, i.e. when $p=1$, the equilibrium quantity collapses to the standard Cournot level which is monotonically decreasing in the number of firms $N$. Similarly Figure 2 shows that the optimal degree of competition decreases with the parameter $b$ : when $b$ for instance takes value 2 and $p=0.5, q^{*}$ becomes monotonically decreasing in $N$. 


\section{Entry through acquisition}

In this section we extend our analysis by relaxing the assumption that only incumbent firms can acquire PAs of failing rivals and allowing for outsiders to participate in the auction. Two cases are studied separately since they give different equilibrium results: either a single entrant is ready to enter, or multiple outsiders compete for entrance.

\subsection{A single outsider}

The outsider stands a fixed entry cost $E$ to be able to operate in the industry. Its reservation value for a failing incumbent firm's PAs amounts to

$$
P_{N} \widehat{q}-E-0
$$

which we assume to be higher than zero: $\widehat{q}$ is the symmetric Cournot equilibrium quantity with one outsider, hence $P_{N} \widehat{q}-E$ represents the outsider's revenue when entering the market after buying a failing firm's PAs and bearing entry cost $E$, whilst zero is the outsider's revenue in case it stays out of the market.

Here inside bidders have a higher reservation value than the outsider due to cost $E$ borne only by the latter. Following the Bertrand argument of section 3, we assume that the equilibrium bid is the second highest reservation value plus a small amount $\varepsilon$. As a consequence, two differences arise compared to the scenario without outsiders: when only one insider is healthy, it outbids by $\varepsilon$ the outsider's reservation value (19); when there is no healthy insider, the outsider bids $\varepsilon$. The equilibrium bids in (15) are thus

$$
v_{N}(1, H) \equiv\left\{\begin{array} { l l } 
{ 0 } & { \text { if } H = N - 1 , } \\
{ P _ { N } \widehat { q } } & { \text { if } H \in [ 1 , N - 2 ] , } \\
{ P _ { N } \widehat { q } - E + \varepsilon } & { \text { if } H = 0 , }
\end{array} \quad \text { and } v _ { N } ( 0 , H ) \equiv \left\{\begin{array}{ll}
P_{N} \widehat{q} & \text { if } H \in[2, N-1] \\
P_{N} \widehat{q}-E+\varepsilon & \text { if } H=1, \\
\varepsilon & \text { if } H=0
\end{array}\right.\right.
$$

Given that the lender's individual rationality constraint is binding, the choice of the quantity in equilibrium requires maximizing the expected surplus:

$$
U_{i}=\left[1-(1-p)^{N}\right] P_{N} q_{i}+(1-p)^{N} \varepsilon-q_{i}^{2}
$$

Therefore the symmetric Cournot equilibrium quantity is the following:

Proposition 3 When a single outsider participates in the auction for productive assets, the symmetric equilibrium quantity in the Cournot game with $N$ incumbent firms is

$$
\widehat{q}=S \frac{1-(1-p)^{N}}{2+b(N+1)\left[1-(1-p)^{N}\right]} .
$$

Proof. In the Appendix. 


\subsection{Multiple outsiders}

Let us assume that several homogeneous outsiders compete with insiders in the auction for second-hand PAs. Outsiders bear a fixed entry cost $E$ per productive asset to be able to operate in the industry, hence a representative outsider's reservation value for a failing incumbent firm's PAs is as in (19). There is a difference with respect to the scenario with a single outsider: when all insiders fail, the outsiders compete by bidding up to (19). The equilibrium bids for a failing firm's PAs are thus

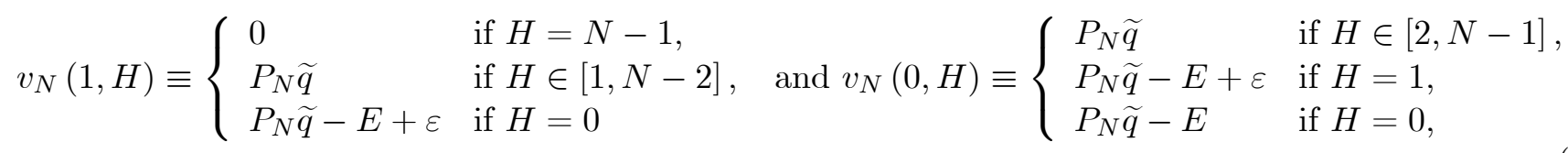

where $\widetilde{q}$ is the symmetric Cournot equilibrium quantity with multiple outsiders.

Given that the lender's individual rationality constraint is binding, the choice of the quantity in equilibrium requires maximizing the expected surplus:

$$
U_{i}=P_{N} q_{i}-(1-p)^{N} E-q_{i}^{2}
$$

Finally, we compute the symmetric Cournot equilibrium quantity:

Proposition 4 When multiple outsiders participate in the auction for productive assets, the symmetric equilibrium quantity collapses to the quantity in the standard Cournot game with $N$ firms, that is

$$
\widetilde{q}=\frac{S}{2+b(N+1)}
$$

Proof. In the Appendix.

When there are multiple outsiders participating in the auction for the PAs of the failing incumbent firms, our model collapses to the standard Cournot equilibrium, similarly to the case of $p=1$. Here competition yields no benefit as the Cournot quantity decreases with the number of incumbent firms in the industry. Interestingly, the equilibrium quantity with a single outsider, (22), lies in between the equilibrium quantity without outsiders (17) and that with multiple outsiders (25), as one can check in the following figure, where we plot $q^{*}, \widehat{q}$ and $\widetilde{q}$ as a function of $N$, given $b=0.1$ and $p=0.5$. 
Figure 3

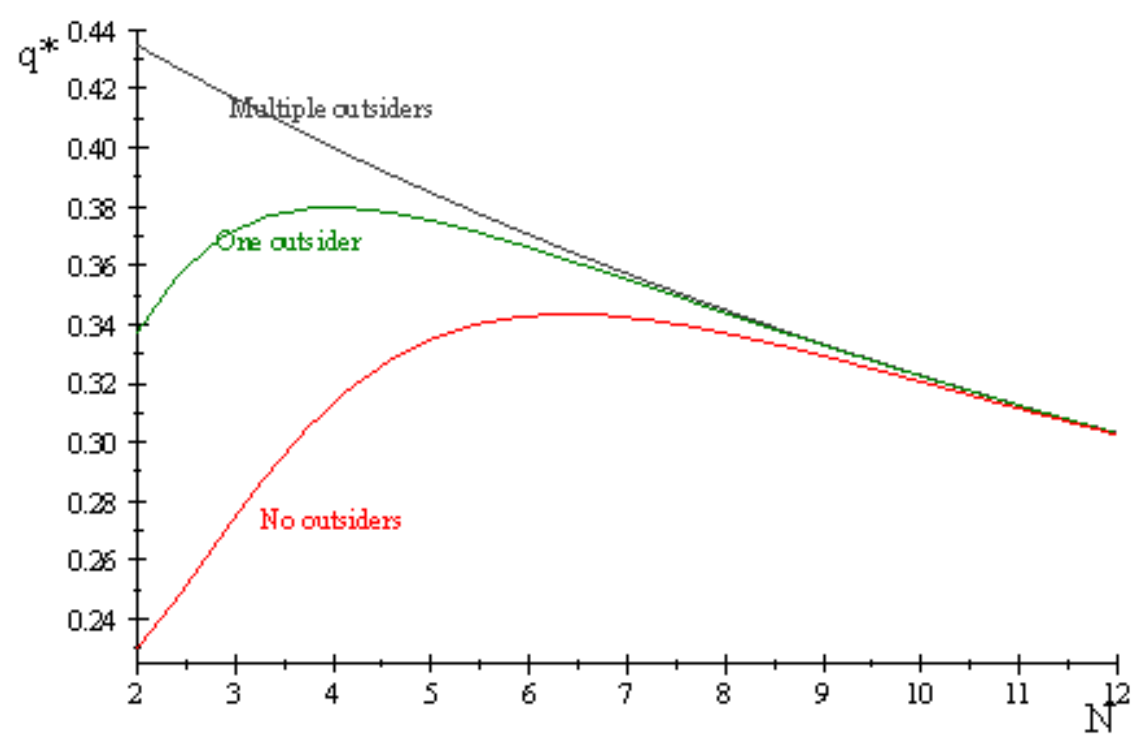

We can conclude that the equilibrium quantity $q^{*}$ (and thus the level of new debt on investment in equilibrium $L^{*}$ ) is positively affected by the number of outside buyers of PAs. Instead, the positive effect of competition on $q^{*}$ and $L^{*}$ is washed out. Indeed, Figure 3 shows that the optimal degree of competition, i.e. the number of firms $N$ that maximizes $q^{*}$, decreases with the number of outsiders and $q^{*}$ becomes monotonically decreasing in $N$ when multiple outsiders are present.

\subsection{Empirical predictions}

The model presented in the previous sections allows us to derive empirical predictions on the amount of credit available to firms by relating it to the structure of the product market where they operate. More precisely, the theory suggests a positive effect of greater product market competition on credit available to firms willing to invest. In addition the model shows that the result about greater product market competition on the percentage of investment financed with new debt is affected by the presence of outside competitors who may find the opportunity to enter the market through the acquisition of liquidated PAs.

When we test the empirical predictions of the theoretical analysis on Italian firms, we must take into account several important considerations based on the theoretical model. The relation between additional debt and equilibrium quantity in (18) depends upon the amount of own funds $M$ : hence firms with greater availability of inside funds can invest more for a given amount of debt. In addition there might be a minimum investment $\bar{I}$ necessary to build an efficient plant, so that production takes place only if $I_{i} \geq \bar{I}$ : then we might observe firms that choose not to invest.

In the empirical analysis it is important to take into account these forms of heterogeneity among firms. First, the existence of different levels of own funds $M$ implies that it is possible to observe firms that have 
invested although their decision was not affected by the mode of financing since the availability of own funds allowed them to split these two choices. Second, if there is a minimum level of investment to achieve efficiency then we might observe firms that did not invest although not financially constrained. Although it is important to observe that the notion of credit availability is driven in the model by the need to invest in productive projects, in the empirical analysis the choice of investment and its mode of financing may not be perfectly correlated. This implies that it is crucial to apply our analysis on data reporting both the choice to invest and the way the investment is financed.

Finally it is worth stressing that the model does not have implications for the total leverage of the firm, but simply for the proportion of new debt used to finance the investment. We don't need to observe in the data the information about total debt in the financial structure of firms - i.e. the leverage - but the amount of additional borrowings related to a specific investment.

\section{Empirical test}

The theoretical model delivers predictions on the relation between the percentage of investment financed by collateralized bank debt, competitiveness of the product market, and features of the collateral's market. Any attempt to bring the model to the data must deal with advantages and disadvantages of alternative sources of information.

One possible choice is to use credit register data reporting information on each single debt contract, borrowers' characteristics and the nature of the collateral. These data provide a detailed picture of the existing financial contracts, product and collateral markets conditions. However - by construction - such data refer only to companies that were succesful in obtaining financial support by the bank, not companies that did not invest or self-financed their investments. This creates a potential issue of endogeneity in sample selection, given that investment and financing strategies are in fact joint decisions. Should the endogeneity issue be relevant, the results based on register data could not be extended to the entire population of companies. Furthermore register data would not allow us to study how a change in the competitiveness of the product market affects the percentage of companies financing their investment through collateralized debt because these data do not provide information on companies that have not invested or have selffinanced their investment. For this reason it is advisable to use sources of data covering both investing and not investing firms, collecting information about the way the investment is financed and distinguishing between bank debt and self-finance.

Another possibility is to use large datasets with firms' accounting data, now easily available in many industrialized countries. In this way we could measure the amount of company outstanding debt, eventually its variation over time, but we could not associate it to a specific investment. This association is crucial for our purpose, given that we focus on investments (and collaterals) tied to the specific economic activity of 
the company. We therefore need to distinguish between equipment or machinery investments (and related loans) - which are clearly activity specific - and other less specific investments (e.g. real estate, and related loans). Another reason why accounting data would be unsuitable for our purpose is that we need to associate a specific investment to the way it is financed, hence we require information on the incremental debt not on the total outstanding debt of the firm as it is reported in the accounting records.

Information about the nature of the investment and the way it is financed is gathered sometimes through surveys. This is the case of the Survey on the access to finance of Italian Manufacturing Enterprises, run by Unicredit Bank Group every three years. Here we use the 10th wave of that survey, which gathers self reported data for the years 2004-2006 on a representative sample of about 5000 manufacturing companies with more than 10 employees. The information contained in the survey is linked to the company accounting records taken from AIDA for the years 2000-2006. The data provide information on the location of the firms and a detailed description of their operation. We can therefore associate each company in the sample to the competitive conditions in the local credit and product markets.

Given the specificities of the available data, in our empirical exercise we follow a reduced form approach. We observe the choice to invest of firms and, conditional on that, the fraction of the investment financed by medium to long term bank debt. Both are outcomes of the interaction of demand and supply conditions in the credit market, that are not explicitly modelled. We therefore abstain from giving a causality interpretation of our results, but nevertheless we use them to evaluate the predictive power of our theoretical model.

Due to missing values in some of the relevant variables we consider 3,437 out of the 5,134 companies surveied (see Table 1). The survey first asks firms whether they have invested in equipments or machineries in the period 2004-2006. Then it asks the 2,514 companies who answered positively to the previous question (73\%), how were those investments financed: $43 \%$ of them entirely self-financed their investments or did not resort to any medium to long term bank debt, and finally $27 \%$ relied exclusively on medium to long term bank debt. Notice that direct access to the bond market or to venture capital finance is extremely rare for Italian SMEs, and in fact it is absent in our sample.

To be consistent with the theoretical model, we focus on medium and long term bank debt, as this is the kind of debt potentially requiring collateral. We don't actually have information on the presence of any collateral in the debt contract, nor on the nature of the collateral (which might not be the same productive asset to which the company refers in the question about investments). This information is available only in credit registers on collateralized debt contracts, whose drawbacks however have been discussed at the beginning of this section. We therefore rely on an imperfect measure of collateralized debt which is likely to overestimate the incidence of collaterals in companies' external finance.

Again, we can infer that $43 \%$ of the companies that have invested in the period 2004-2006 did not use any medium to long term bank debt. Among those relying on debt, $48 \%$ used exclusively it. These statistics 
suggest that the decision on how much debt to use can be modelled as a two part process: first a decision on whether to invest and to resort to debt, then, for those who decided to finance their investment with debt, the choice of the percentage of the investment financed with bank debt. We study the decision to use bank debt taking into account that the outcome of this choice is observable only for those companies that actually invested, and that their investment decision is potentially dependent upon the mode of financing. Therefore we use a probit model with sample selection ${ }^{6}$ for the first part of the decision process:

$$
I_{i}=\mathbf{1}\left(x_{1 i}^{\prime} \beta_{1}+\varepsilon_{1 i}\right)>0 \quad D_{i}= \begin{cases}\mathbf{1}\left(x_{2 i}^{\prime} \beta_{2}+\varepsilon_{2 i}>0\right) & \text { if } I_{i}=1 \\ \text { not observed } & \text { if } I_{i}=0\end{cases}
$$

where $I_{i}$ is a dummy equal to 1 if company $i$ has undertaken investments in the interval 2004-2006, and zero otherwise; $D_{i}$ is equal to 1 if company $i$ has raised additional bank debt ${ }^{7}$ to finance this specific investment; $\mathbf{1}($.$) is an indicator function, which equals 1$ whenever the condition inside brackets holds true; $x_{1 i}$ and $x_{2 i}$ are $k_{1} \times 1$ and $k_{2} \times 1$ vectors of observable characteristics of company $i$. Finally the error components $\varepsilon_{1 i}$ and $\varepsilon_{2 i}$ are jointly normally distributed according to:

$$
\left(\begin{array}{c}
\varepsilon_{1 i} \\
\varepsilon_{2 i}
\end{array}\right) \mid x_{1 i}, x_{2 i} \sim N\left\{\left(\begin{array}{l}
0 \\
0
\end{array}\right),\left(\begin{array}{cc}
1 & \rho \\
\rho & 1
\end{array}\right)\right\}
$$

Once the company has decided to invest and to resort to debt (i.e. $I_{i}=1$ and $D_{i}=1$ ), the firm chooses the percentage of the investment to be financed with additional debt $L_{i} \in[0,100 \%]$. We assume

$$
\ln L_{i}=\left\{\begin{array}{cl}
x_{3 i}^{\prime} \beta_{3}+\varepsilon_{3 i} & \text { if } x_{3 i}^{\prime} \beta_{3}+\varepsilon_{3 i}<\ln 100 \\
\ln 100 & \text { if } x_{3 i}^{\prime} \beta_{3}+\varepsilon_{3 i} \geq \ln 100
\end{array}\right.
$$

with $\varepsilon_{3 i} \mid\left(x_{i}, I_{i} \times D_{i}=1\right) \sim N\left(0, \sigma^{2}\right)$, where $x_{i}=\left(x_{1 i}^{\prime}, x_{2 i}^{\prime}, x_{3 i}^{\prime}\right)^{\prime}$ is the $\left(k_{1}+k_{2}+k_{3}\right) \times 1$ vector of all the variables included in the model. Altogether, we use a generalization of the two-part model suggested by Duan et al. (1983) in which the first part is a probit model with sample selection (instead of a standard probit) and the second part is a tobit model (instead of a standard linear regression model). Maximum likelihood estimation is straightforward as it breaks the problem into two separate models: a probit model with sample selection on the full sample and a tobit model on the subset of observations such that $I_{i} \times D_{i}=1$. Considering the entire population of companies, the two-part model defines the expected percentage of investment financed with new debt as:

$$
E\left[L_{i} \mid x_{i}\right]=\operatorname{Pr}\left(I_{i} \times D_{i}=1 \mid x_{i}\right) \exp \left(E\left[\ln L_{i} \mid x_{i}, I_{i} \times D_{i}=1\right]+\frac{\sigma^{2}}{2}\right)
$$

Equation (27) implies that for any company $i$ a change in any explanatory variable $k$ included in $x_{i}$, defined as $x_{i}^{k}$, may affect $L_{i}$ in two ways: either by changing the probability that company $i$ finances the investment

\footnotetext{
${ }^{6}$ See Van de Ven and Van Pegg (1981) among others for the use of probit models with sample selection.

${ }^{7}$ It is important to stress that $D$ is the additional bank debt and not the company's total leverage as reported in its balance sheet. Our variable $D$ refers to the additional debt used for the purpose of this specific investment, while leverage refers to the stock of debt, that has not reached its maturity yet, raised for other reasons in the past history of the company. This makes our dataset based on surveys more suitable for testing our model compared to other sources relying on accounting data.
} 
with debt, given by $\operatorname{Pr}\left(I_{i} \times D_{i}=1 \mid x_{i}\right)$, and/or by affecting the percentage of additional debt given that the company is already a borrower, $E\left[\ln L_{i} \mid x_{i}, I_{i} \times D_{i}=1\right]$. The marginal effect of $x_{i}^{k}$ on $E\left[L_{i} \mid x_{i}\right]$ is therefore a function of the parameters of both parts of the empirical model $\theta=\left(\beta_{1}^{\prime}, \beta_{2}^{\prime}, \beta_{3}^{\prime}, \sigma^{2}\right)^{\prime}$, more specifically:

$$
\begin{aligned}
\frac{\partial E\left[L_{i} \mid x_{i}\right]}{\partial x_{i}^{k}}= & E\left[L_{i} \mid x_{i}\right]\left[\frac{\partial \operatorname{Pr}\left(I_{i} \times D_{i}=1 \mid x_{i}\right)}{\partial x_{i}^{k}} \frac{1}{\operatorname{Pr}\left(I_{i} \times D_{i}=1 \mid x_{i}\right)}\right. \\
& \left.+\beta_{3}^{k} \operatorname{Pr}\left(L_{i}<100 \mid x_{i}, I_{i} \times D_{i}=1\right)\right] .
\end{aligned}
$$

We consider the double choice whether to invest and how to finance the investment to be a function of firm's financial position and profitability at the beginning of the reference period, that is at the end of the year 2003. More specifically we include in $x_{j i}$ with $j=\{1,2,3\}$ accounting information to control for firm's size (measured as (log of) turnover), leverage (defined as the ratio of total debt over total assets), the ratio of fixed to total assets and profitability (measured as ROA). We also compute for each company in the sample the z-score proposed by Altman (2002) as a measure of the company's riskiness based on accounting variables at 2003

$$
\text { z-score }=6.56 f_{1}+3.26 f_{2}+6.72 f_{3}+1.05 f_{4}
$$

where $f_{1}$ is the ratio between working capital and total assets, $f_{2}$ is the change in "other shareholders funds" over total assets between 2002 and 2003, $f_{3}$ is the ratio between EBIT and total assets, and $f_{4}$ is the ratio between shareholders funds and the sum of non current liabilities plus current liabilities. A low z-score is considered to be a predictor of a high probability of default $(p)$ which itself might affect the percentage of the investment financed with debt according to our theoretical model.

Furthermore, we include dummy variables to indicate whether the company is listed in the stock market, whether it is younger than 10 years $($ age $<10)$ or part of a larger industrial group. We control for the degree of competition in the banking sector in the market where the firm is located by including the Herfindahl index on bank branches. ${ }^{8}$

The structure of the product market instead is captured by the (log of the) Herfindahl index computed using the distribution of plants operating in the same 2-digit Ateco industry and in the province where the company is located. According to our theoretical model, a low level of competition may reduce the value of the collateral in case of default, and thus may be associated to a lower credit availability to firms. This effect should be stronger if the main competitors (which are the potential buyers of the productive asset in case of default) are all within the region. In fact the model predicts that the existence of rivals outside the local market willing to bid in order to acquire the productive asset reduces the beneficial effect of product market competition on debt. We therefore add a dummy variable which equals one if the competitors of the company are all in the same region of the company itself and interact it with the log of the Herfindahl index for the local product market.

\footnotetext{
${ }^{8}$ This information is taken from Cerasi et al. (2009) where the number of branches of individual banks in each local market is used to estimate an index of competition in the banking sector.
} 
In order to improve the identification of the parameters of the model, we consider a set of variables to be included in $\left(x_{1}, x_{2}\right)$ but not in $x_{3}$, that is, variables which determine whether to invest and to resort to debt, but that do not affect the choice of the amount of debt, once the decision to resort to debt has been taken. These are industry dummy variables (2-digit Ateco codes) and a measure of the liquidity of the company given by the (log of the) ratio between the reserves and total assets. For the same reason we include the (log of the) number of employees and the (log of the) fixed assets to turnover ratio in $x_{1}$ but not in $x_{2}$ and $x_{3}$. That is, we assume that labor and capital intensity affect the investment decision, but not the amount of debt conditional on having invested.

The sample average of the explanatory variables are reported in Table 1, where the observations are divided into subsets according to the different investment and financing choices

[Insert Table 1 here]

The companies in our sample have at the end of 2003 a turnover worth on average between 4.4 and 8.7 millions of Euro, with those not investing being the smallest ones. The ROA is about $4 \%$, with an overall leverage above $60 \%$. The vast majority of companies are independent companies, not part of a group and older than 10 years. It is therefore a sample of relatively large Italian SMEs, with a long history and mainly operating in traditional sectors. About 30\% of those not investing in the period 2004-2006, have only local competitors, that is rivals within the boundaries of their region. This percentage drops to $22 \%$ among those investing. The competitiveness of the local bank markets seems not to differ between companies that invested compared to those that have not invested. On the contrary, the local product markets of the investing companies are more concentrated than of those not investing.

The pseudo-maximum likelihood estimates of the probit model with sample selection and the tobit model are presented in Table 2. Given the non-linearity of the empirical models, the effect of the covariates on the outcomes can be captured by the average marginal effects shown in Table 3. The results show that the probability of investing increases with the profitability of the company, and the company age, for instance due to the need to replace the old equipment. Ceteris paribus, companies with higher fixed assets over turnover ratio and more personnel are more likely to invest in equipments and machineries in the period 2004 to 2006. Firms with only regional competitors are remarkably less likely to invest.

[Insert Table 2 and 3 here]

The probability of using bank debt to finance a specific investment during the period 2004-2006 is increasing in the amount of leverage at the end of 2003 and higher for independent companies that cannot rely on intra-group transfers. The more liquid is the company the more it resorts to debt, probably because 
banks expect a higher solvency to be associated to greater liquidity. Once controlling for all other indicators, the z-score does not help to predict neither the investment choice, nor the choice on how to finance it.

A lower concentration in the local banking sector increases the probability of choosing bank debt to finance investments. The structure of the bivariate probit model allows us to better understand the channel through which the explanatory variables affect the probability of the joint event $\operatorname{Pr}\left(I_{i}=1, D_{i}=1 \mid x_{i}\right)$. We can observe for instance that such a probability increases with the ROA due to the positive effect on the probability to invest, although its effect on the choice of debt is negligible. The reverse holds for competitiveness in the local bank sector, it is relevant for $\operatorname{Pr}\left(D_{i}=1, x_{i}\right)$ and $\operatorname{Pr}\left(D_{i}=1 \mid I_{i}=1, x_{i}\right)$ but not for the joint probability. The estimated measure of correlation among the two choices, $\rho(-0.53)$, suggests that the investment and the financing decision are negatively correlated: ceteris paribus, the higher the probability to invest, the lower the probability to finance the investment with bank debt. This evidence confirms the fact that Italian SMEs tend to self-finance their investments, otherwise they prefer not to invest at all.

We now turn our attention to the percentage of the investment financed with new bank debt, focusing on those companies which actually financed their investment with bank debt (i.e. those with $I_{i} \times D_{i}=1$ ). The last columns of Tables 2 and 3 show the results for this second part of the model. Larger companies use a lower percentage of debt, companies with higher leverage tend to use more new debt. The previous results on bank sector concentration are confirmed here, but what is more relevant for our aim is how the index of competitiveness in product market affects the percentage of debt for these companies: the more concentrated is the product market the lower is the percentage of debt. Furthermore the effect is much stronger for those companies without competitors outside their area (with an elasticity of -0.04 versus -0.01 ).

We now use the estimated parameters in Table 2 togheter with the value of the observable characteristics $x_{i}$ for all the companies in the sample to assess to what extent the competitiveness in the product market affects the expected ratio of new debt over investment in the entire sample of companies, that is for each firm we compute the semi-elasticity $\partial E\left[L_{i} \mid x_{i}\right] / \partial \ln H_{i}$ according to equation (28). The average semi-elasticity is estimated to be -0.8 , not statistically different from zero for those companies with competitors outside the regional boundaries, while it is -3.1 , and statistically different from zero for those companies with only local competitors. Furthermore, the effect is stronger for the firms which actually invested and financed their investment with debt $(-3.3)$, but it is also potentially relevant for those investors who did not resort to medium-long bank debt $(-3.1)$ and for the non-investors $(-2.8)$.

We also considered all possible interactions between explanatory variables related to the structure of the product market and the z-score, but none of these interactions proved to be statistically significant. Since the z-score is a measure of the ex-ante credit worthiness of firms and it is actually captured, among other things, by the real amount of debt and profitability, its interaction with other variables does not add 
explanatory power to the previous model.

In conclusion, our preliminary results show that companies facing more competition in their local product markets are capable of attracting more debt to finance their investment and that this effect is stronger the fewer are the direct competitors outside the local market. This piece of evidence is fully consistent with the predictions of our theoretical model.

\section{Concluding remarks}

In this paper we present a theoretical model that links credit conditions to the structure of the product market in which firms operate not only through the standard effect on prices but also through the resale value of the productive assets used as collateral in the loan contract. Since the resale value of productive assets is enhanced by their liquidity, having more rivals in the industry boosts the value of PAs in case of liquidation. However more competition shrinks profits. The final effect on the pledgeable income to creditors is the result of the above trade-off. We suggest possible determinants of the trade-off and leave to the empirical analysis the task of measuring its actual impact on financial conditions for SMEs. In the empirical analysis on Italian SMEs we test the effect of product market conditions on the ability to raise external debt. We provide supportive evidence to our theoretical result, in that companies facing greater product market competition and without outside bidders succeed in raising more bank debt to finance their investments.

In the theoretical model we make several restrictive assumptions for analytical tractability. For instance we assume independence across defaults for all firms in the market: this assumption is indeed relaxed in the empirical analysis. Furthermore we assume independence between probability of default and product market competition. If competition increases the probability of default our mechanism might even be stronger. However if the opposite was true our result might be weakened. The link between firms' default rates, product market competition and bank debt has been preliminarly analyzed within our empirical model, by introducing the degree of riskiness of companies measured with the z-score; however we have not found any significative evidence in support to this relation. 


\section{References}

[1] Acharya V., Bharath S., Srinivasan A., 2007, Does Industry-wide Distress Affect Defaulted Firms? Evidence from Creditor Recoveries, Journal of Financial Economics, 85(3), 787-821.

[2] Almeida H., Campello M., Hackbarth D., 2009, Liquidity Mergers, AFA 2010 Atlanta Meetings Paper. Available at SSRN: http://ssrn.com/abstract $=1362327$

[3] Altman, E., 2002, Predicting Financial Distress of Companies: Revisiting the Z-Score and Zeta Models, New York University Working Papers.

[4] Amemiya T., 1985, Advanced Econometrics. Harvard University Press.

[5] Benmelech E. and N.K. Bergman, 2009, Collateral Pricing, Journal of Financial Economics, 91(3), 339-360.

[6] Benmelech E. and N.K. Bergman, 2011, Bankruptcy and the Collateral Channel, Journal of Finance, $66(2), 337-378$.

[7] Berger A. and G. Udell, 1995, Relationship Lending and Lines of Credit in Small Firm Finance, The Journal of Business, 68 (3), 351-381.

[8] Brander J. and T. Lewis, 1986, Oligopoly and Financial Structure: The Limited Liability Effect, American Economic Review, 76 (5), 956-970.

[9] Cerasi V., Chizzolini B., and Ivaldi M., 2009, The impact of mergers on the degree of competition in the banking industry, CEPR Discussion Paper No. 7618.

[10] Cerasi, V. and A. Fedele, 2011, Does Product Market Competition Increase Credit Availability?, The B.E. Journal of Economic Analysis 63 Policy, Vol. 11: Iss. 1 (Topics), Article 41.

[11] Colombo M. and Grilli L., 2007, Funding Gaps? Access To Bank Loans By High-Tech Start-Ups, Small Business Economics, 29(1), 25-46.

[12] Gavazza A., 2010, Asset Liquidity and Financial Contracts: Evidence from Aircraft Leases, Journal of Financial Economics, 95(1), 62-84.

[13] Habib M. and B. Johnsen, 1999, The Financing and Redeployment of Specific Assets, Journal of Finance, 54 (2), 693-720.

[14] Holmstrom B. and J. Tirole, 1997, Financial Intermediation, Loanable Funds and the Real Sector, Quarterly Journal of Economics, 112 (3), 663-691. 
[15] Ortiz-Molina H. and G. Phillips, 2009, Asset Liquidity and the Cost of Capital, Available at SSRN: http://ssrn.com/abstract $=1413780$

[16] Rajan R., 1992, Insiders and Outsiders. The Choice between Informed and Arm's-Lenght Debt, Journal of Finance, 48(4), 1367-1400.

[17] Rajan R., Zingales L., 1998, Financial Dependence and Growth, American Economic Review, 88 (3), 559-586.

[18] Shleifer A. and R. Vishny, 1992, Liquidation Values and Debt Capacity: a Market Equilibrium Approach, Journal of Finance, 47(4), 1343-1366.

[19] Van de Ven W. P. M. M., and Van Pragg B. M. S., 1981, The demand for deductibles in private health insurance: A probit model with sample selection, Journal of Econometrics, 17, 229-252. 


\section{A Proofs}

Proof of Proposition 1: Firm $i$ 's expected revenue at date 0 given that in the symmetric Cournot equilibrium all firms but $i$ choose the same quantity $q^{*}$ is computed as follows. With probability $(1-p)$ firm $i$ fails, hence its returns go to zero due to limited liability. By contrast, with probability $p$ firm $i$ actually competes in the product market by gaining $P_{N} q_{i}$ and repaying $r_{i}$ at date 1 . In addition, firm $i$ earns the following extra-revenue

$$
\sum_{H=0}^{N-1}\left(\begin{array}{c}
N-1 \\
H
\end{array}\right) p^{H}(1-p)^{N-1-H} \frac{1}{H+1} P_{N}(N-1-H) q^{*}:
$$

when $N-1-H$ rivals are in distress - this occurs $\left(\begin{array}{c}N-1 \\ H\end{array}\right)$ times, each one with probability $p^{H}(1-p)^{N-1-H}$ - firm $i$ is awarded PAs of all distressed rivals with probability $\frac{1}{H+1}$. Summing up, firm $i$ 's expected revenue is:

$$
U_{i} \equiv p\left(P_{N} q_{i}-r_{i}\right)+p \sum_{H=0}^{N-1}\left(\begin{array}{c}
N-1 \\
H
\end{array}\right) p^{H}(1-p)^{N-1-H} \frac{1}{H+1} P_{N}(N-1-H) q^{*}-M,
$$

where $M$ is the opportunity cost of firm's own funding.

The expected revenue accruing to a bank when funding firm $i$. With probability $p$ firm $i$ is healthy, repays $r_{i}$ but requires extra-borrowing to bid for the distressed rivals' PAs at unit price $v_{N}(1, H)$. With probability $(1-p)$ firm $i$ fails, hence the bank seizes PAs and recovers liquidation value $v_{N}(1, H)$ from an auction with $H$ bidding firms over $N$ initial competitors. In symbols

$$
\begin{aligned}
V_{i} \equiv & p\left[r_{i}-\sum_{H=0}^{N-1}\left(\begin{array}{c}
N-1 \\
H
\end{array}\right) p^{H}(1-p)^{N-1-H} \frac{1}{H+1}(N-1-H) v_{N}(1, H)\right] \\
& +(1-p)\left[\sum_{H=0}^{N-1}\left(\begin{array}{c}
N-1 \\
H
\end{array}\right) p^{H}(1-p)^{N-1-H} v_{N}(0, H)\right]-\left(I_{i}-M\right),
\end{aligned}
$$

with $v_{N}(0, H) \equiv P_{N} q_{i}$ for $H \in[2, N-1]$. Substituting the equilibrium bids from (15), the bank's expected revenue on the loan to firm $i$ can be rewritten as:

$$
\begin{aligned}
V_{i} \equiv & p\left[r_{i}-\sum_{H=1}^{N-1}\left(\begin{array}{c}
N-1 \\
H
\end{array}\right) p^{H}(1-p)^{N-1-H} \frac{1}{H+1} P_{N}(N-1-H) q^{*}-(1-p)^{N-1}(N-1) \varepsilon\right] \\
& +(1-p)\left[(N-1) p(1-p)^{N-2} \varepsilon+\sum_{H=2}^{N-1}\left(\begin{array}{c}
N-1 \\
H
\end{array}\right) p^{H}(1-p)^{N-1-H} P_{N} q_{i}\right]-\left(I_{i}-M\right) .
\end{aligned}
$$

At date 0 each firm $i$ solves the following problem: it sets quantity $q_{i}$ and repayment $r_{i}$ with the aim of maximizing $U_{i}$, given the bank's participation constraint $V_{i} \geq 0$ and taking as given the quantity set by other rivals. In symbols

$$
\max _{q_{i}, r_{i}} U_{i}
$$

$$
\text { s.t. } V_{i} \geq 0 \text { and } q_{j}=q^{*} \text { for all } j \neq i \text {. }
$$

We know that constraint $V_{i} \geq 0$ is binding at the solution to problem (32): solving $V_{i}=0$ by $r_{i}$ and substituting into (30) gives

$$
U_{i}=\left[p+(1-p) \sum_{H=2}^{N-1}\left(\begin{array}{c}
N-1 \\
H
\end{array}\right) p^{H}(1-p)^{N-1-H}\right] P_{N} q_{i}+p(1-p)^{N-1} P_{N}(N-1) q^{*}-q_{i}^{2}
$$


The previous formula can be interpreted similarly to (10). Firm $i$ earns $P_{N} q_{i}$ when either it is successful (with probability $p$ ) or when it fails and at least two rivals are healthy (with probability given by the binomial function when there are $H \geq 2$ bidders among $N-1$ firms), thus bidding $v_{N}(0, H) \equiv P_{N} q_{i}$ to acquire firm $i$ 's PAs. In addition firm $i$ gains an extra revenue when, by being healthy, bids in a single-bidder auction and acquires all $N-1$ failing rivals' PAs (with probability $p(1-p)^{N-1}$ ). In all other cirumstances the overall gain is zero. The last term is the cost of producing quantity $q_{i}$.

Finally, observe that

$$
\sum_{H=2}^{N-1}\left(\begin{array}{c}
N-1 \\
H
\end{array}\right) p^{H}(1-p)^{N-1-H}=1-(1-p)^{N-1}-(N-1) p(1-p)^{N-2}
$$

according to the Binomial density formula. Substituting (34) into (33) and taking the derivative with respect to $q_{i}$, when all rivals set their quantity at the equilibrium level $q^{*}$, yields the symmetric Cournot equilibrium quantity in a $N$-oligopoly:

$$
q^{*}=S \frac{1-(1-p)^{N-1}[1+p(N-2)]}{2+b\left\{N+1-(1-p)^{N-1}\left[N+1+p(N-1)^{2}-2 p\right]\right\}}
$$

We then verify that condition (14) is fulfilled at equilibrium. Plugging $q^{*}$ into (14) one can easily check that it rewrites as

$$
\frac{2+(N-1) b p(1-p)^{N-1}}{2+b\left\{N+1-(1-p)^{N-1}\left[N+1+p(N-1)^{2}-2 p\right]\right\}}
$$

which is positive.

Proof of Proposition 3: Representative firm $i$ 's expected revenue is as in (30). On the contrary, expected return of the bank lending to firm $i$ is derived by substituting the equilibrium bids (20) into (31):

$$
\begin{gathered}
V_{i} \equiv p\left[r_{i}-\sum_{H=1}^{N-1}\left(\begin{array}{c}
N-1 \\
H
\end{array}\right) p^{H}(1-p)^{N-1-H} \frac{1}{H+1}(N-1-H) P_{N} \widehat{q}-(1-p)^{N-1}\left(P_{N} \widehat{q}-E+\varepsilon\right)\right] \\
+(1-p)\left[(1-p)^{N-1} \varepsilon+(N-1) p(1-p)^{N-2}\left(P_{N} q_{i}-E+\varepsilon\right)+\sum_{H=2}^{N-1}\left(\begin{array}{c}
N-1 \\
H
\end{array}\right) p^{H}(1-p)^{N-1-H} P_{N} q_{i}\right] \\
-\left(I_{i}-M\right) .
\end{gathered}
$$

Rearranging yields

$$
\begin{gathered}
V_{i}=p\left[r_{i}-\sum_{H=0}^{N-1}\left(\begin{array}{c}
N-1 \\
H
\end{array}\right) p^{H}(1-p)^{N-1-H} \frac{1}{H+1} P_{N}(N-1-H) \widehat{q}\right] \\
+(1-p)\left[(1-p)^{N-1} \varepsilon+\sum_{H=1}^{N-1}\left(\begin{array}{c}
N-1 \\
H
\end{array}\right) p^{H}(1-p)^{N-1-H} P_{N} q_{i}\right]-\left(I_{i}-M\right) .
\end{gathered}
$$

Given that the constraint $V_{i} \geq 0$ is binding at the solution, we solve $V_{i}=0$ by $r_{i}$ and substitute into (30). This gives the expected surplus in eq. (16). When we take the derivative w.r.t $q_{i}$ and solve for $q_{i}=\widehat{q}$ we obtain the equilibrium quantity in the result. 
Proof of Proposition 4: Representative firm $i$ 's expected revenue is as in (30). On the contrary, expected return of bank lending to firm $i$ is given by (31) after substituting (23):

$$
\begin{gathered}
V_{i} \equiv p\left[r_{i}-\sum_{H=1}^{N-1}\left(\begin{array}{c}
N-1 \\
H
\end{array}\right) p^{H}(1-p)^{N-1-H} \frac{1}{H+1}(N-1-H) P_{N} \widetilde{q}-(1-p)^{N-1}\left(P_{N} \widetilde{q}-E+\varepsilon\right)\right] \\
+(1-p)\left[\sum_{H=0}^{N-1}\left(\begin{array}{c}
N-1 \\
H
\end{array}\right) p^{H}(1-p)^{N-1-H} P_{N} q_{i}-(1-p)^{N-1} E-(N-1) p(1-p)^{N-2}(E-\varepsilon)\right]-\left(I_{i}-M\right) .
\end{gathered}
$$

Rearranging yields

$$
\begin{gathered}
V_{i}=p\left[r_{i}-\sum_{H=0}^{N-1}\left(\begin{array}{c}
N-1 \\
H
\end{array}\right) p^{H}(1-p)^{N-1-H} \frac{1}{H+1}(N-1-H) P_{N} \widetilde{q}\right] \\
+(1-p)\left(\sum_{H=0}^{N-1}\left(\begin{array}{c}
N-1 \\
H
\end{array}\right) p^{H}(1-p)^{N-1-H} P_{N} q_{i}-(1-p)^{N-1} E\right)-\left(I_{i}-M\right)
\end{gathered}
$$

Solving $V_{i}=0$ by $r_{i}$ and plugging into (30) gives the expected surplus in eq. (16). When we take the derivative w.r.t $q_{i}$ and solve for $q_{i}=\widetilde{q}$ we obtain the equilibrium quantity in the result. 
Table 1: descriptive statistics. Averages of the explanatory variables by investment and debt regimes.

\begin{tabular}{l|c|c|c|}
\hline & No investment (I=0) & \multicolumn{2}{|c|}{$\begin{array}{c}\text { Investment (I=1) } \\
\text { No bank debt } \\
\text { (D=0) }\end{array}$} \\
Variables & & 0.7426 & 0.8020 \\
With bank debt \\
Not part of a group & 0.8472 & 0.0852 & 0.1032 \\
Age < 10 yrs & 0.1419 & 5.4974 & 5.2713 \\
zscore_03 & 5.5461 & 0.6174 & 0.6717 \\
Leverage03 & 0.6632 & 2.1680 & 2.0313 \\
Ln(Turnover03) & 1.6362 & 0.2316 & 0.2384 \\
FixTotAss03 & 0.2025 & 0.0495 & 0.0408 \\
ROA03 & 0.0387 & 0.0213 & 0.0098 \\
Listed & 0.0098 & 0.1681 & 0.1632 \\
H local credit market & 0.1628 & 0.2278 & 0.2162 \\
Local competitors only & 0.3034 & -4.6664 & -4.6995 \\
ln(H local industry) & -4.8142 & -2.6212 & -2.7945 \\
Ln(Reserves/TotAssets03) & -2.7465 & 3.8190 & 3.7379 \\
Ln(\# employees) & 3.2796 & 4.9943 & 5.0354 \\
Ln(FixedAssets/Turnover03) & 4.7147 & 1080 & 1434 \\
\hline N. observations & 923 & & \\
\hline
\end{tabular}


Table 2: Pseudo Maximum likelihood estimates.

Two-way cluster adjusted standard errors in parentheses (by province and 2-digit Ateco codes). Equation for $I$ and $D$ include industry dummy variables

\begin{tabular}{|c|c|c|c|}
\hline & (1) & (2) & (3) \\
\hline VARIABLES & $\mathrm{I}=1$ & $\mathrm{D}=1$ & $\ln L$ \\
\hline \multirow[t]{2}{*}{ Not part of a group } & -0.0292 & $0.1914 * * *$ & -0.0148 \\
\hline & $(0.0415)$ & $(0.0666)$ & $(0.0737)$ \\
\hline \multirow[t]{2}{*}{ Age $<10$ years } & $-0.1610 * * *$ & 0.1004 & 0.0082 \\
\hline & $(0.0464)$ & $(0.0746)$ & $(0.0810)$ \\
\hline \multirow[t]{2}{*}{ zscore_03 } & 0.0227 & -0.0151 & 0.0326 \\
\hline & $(0.0240)$ & $(0.0545)$ & $(0.0475)$ \\
\hline \multirow[t]{2}{*}{ Leverage 03} & $0.3409 *$ & $0.9027 * * *$ & $0.4052 *$ \\
\hline & $(0.2057)$ & $(0.2582)$ & $(0.2190)$ \\
\hline \multirow[t]{2}{*}{ Ln(Turnover03) } & 0.0397 & $-0.0443 *$ & $-0.1786 * * *$ \\
\hline & $(0.0320)$ & $(0.0240)$ & $(0.0259)$ \\
\hline \multirow[t]{2}{*}{ FixTotAss03 } & 0.1790 & -0.0508 & 0.3093 \\
\hline & $(0.2741)$ & $(0.4382)$ & $(0.3544)$ \\
\hline \multirow[t]{2}{*}{ ROA03 } & $1.3025 * * *$ & -0.1756 & -0.2424 \\
\hline & $(0.3771)$ & $(0.3733)$ & $(0.5434)$ \\
\hline \multirow[t]{2}{*}{ Listed } & -0.1616 & -0.2165 & 0.3134 \\
\hline & $(0.2653)$ & $(0.1687)$ & $(0.3984)$ \\
\hline \multirow[t]{2}{*}{ H local credit market } & 0.1249 & $-0.6277 * * *$ & $-0.6671 * * *$ \\
\hline & $(0.3796)$ & $(0.1952)$ & $(0.2539)$ \\
\hline \multirow[t]{2}{*}{ Local competitors only } & -0.0628 & -0.3168 & -0.2759 \\
\hline & $(0.1877)$ & $(0.2505)$ & $(0.2034)$ \\
\hline \multirow[t]{2}{*}{$\ln$ (H local industry) } & -0.0196 & 0.0373 & -0.0282 \\
\hline & $(0.0232)$ & $(0.0310)$ & $(0.0197)$ \\
\hline Local competitors only * & 0.0591 & -0.0639 & $-0.0797 * *$ \\
\hline $\ln (\mathrm{H}$ local industry $)$ & $(0.0368)$ & $(0.0463)$ & $(0.0391)$ \\
\hline \multirow{2}{*}{ Ln(Reserves/Tot Assets) } & -0.0115 & $0.0301 * *$ & \\
\hline & $(0.0153)$ & $(0.0122)$ & \\
\hline \multirow[t]{2}{*}{$\ln (\#$ employees) } & $0.2455 * * *$ & & \\
\hline & $(0.0479)$ & & \\
\hline \multirow[t]{2}{*}{$\ln$ (Fixed assets/ turnover) } & $0.0851 * *$ & & \\
\hline & $(0.0397)$ & & \\
\hline \multirow[t]{2}{*}{ Constant } & $-1.0700 * * *$ & 0.2392 & $4.3395 * * *$ \\
\hline & $(0.3646)$ & $(0.5095)$ & $(0.4718)$ \\
\hline \multirow[t]{2}{*}{ Rho } & $-0.5297 * * *$ & & \\
\hline & $(0.1817)$ & & \\
\hline \multirow[t]{2}{*}{ Sigma } & & & $0.8628 * * *$ \\
\hline & & & $(0.0176)$ \\
\hline
\end{tabular}


Table 3: Average marginal effects. Two-way cluster adjusted standard errors in parentheses (by province and 2-digit Ateco codes)

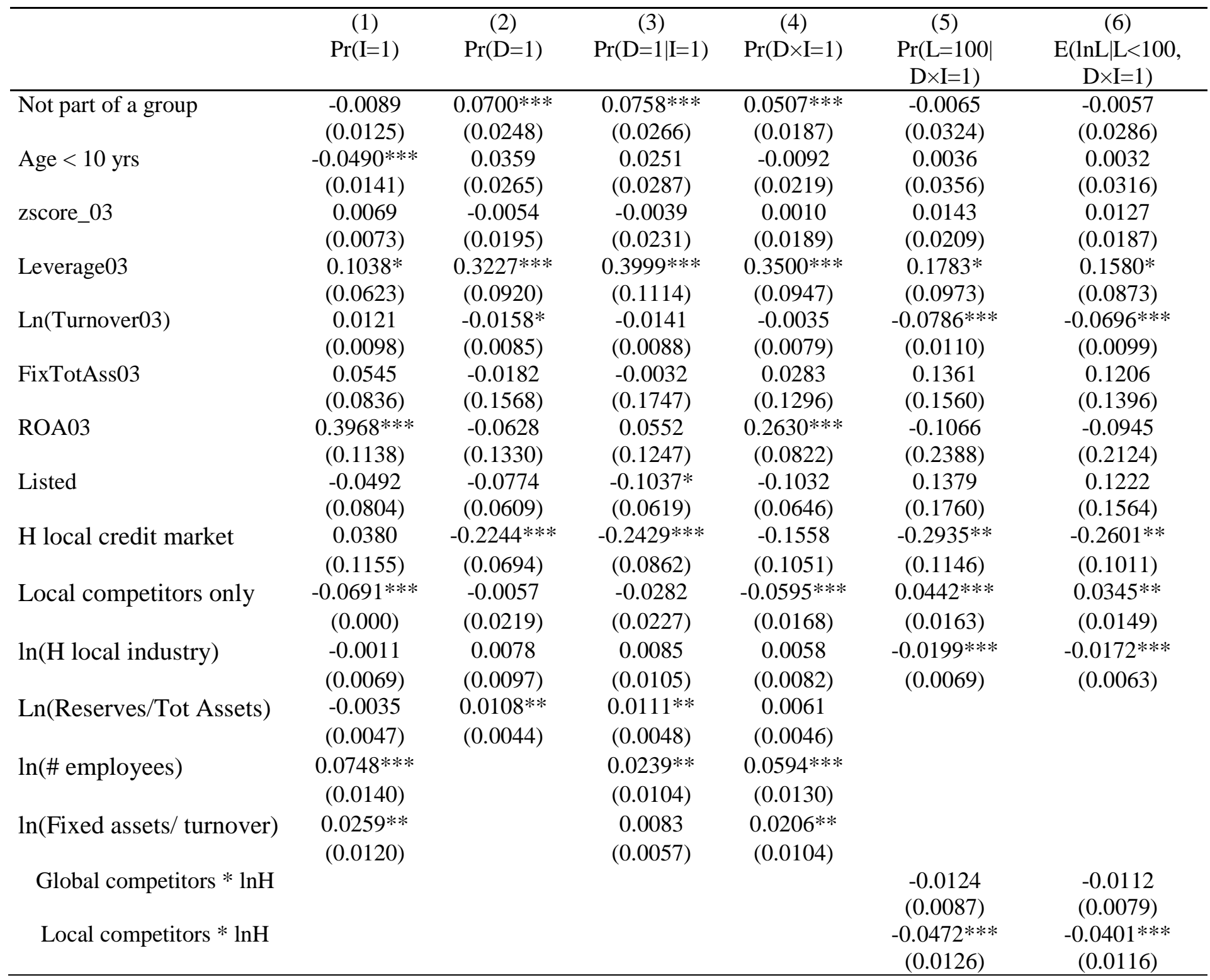

